\title{
Multifocal, recurrent malignant chondroid syringoma with visceral metastases: A case report and literature review
}

\author{
Ann Meredith Garcia1, Jenny Maureen Atun², Gracieux Fernando1 \\ ${ }^{1}$ Section of Medical Oncology, Department of Medicine, University of the Philippines - Philippine General \\ Hospital, Manila, Philippines \\ ${ }^{2}$ Department of Pathology and Laboratories, University of the Philippines - Philippine General Hospital, Manila, Philippines
}

Received December 11, 2015; Revised February 09, 2016; Accepted February 12, 2016; Published Online February 15, 2016

Case Report

\begin{abstract}
We present the unusual case of malignant chondroid syringoma (MCS) in a 64-year-old male with recurrent nodular skin lesions and visceral metastases. The patient underwent repeated excisions, with eventual development of widespread nodules and multiple pulmonary and hepatic nodules. Systemic chemotherapy was planned. MCS is a very rare skin adnexal tumor of the sweat glands with only around 50 cases reported worldwide. To the authors' knowledge, this is the first reported case of MCS with a multifocal presentation and mucosal involvement.
\end{abstract}

Keywords: Malignant Chondroid Syringoma; Malignant Mixed Tumor; Sweat Gland Carcinoma; Eccrine Carcinoma; Adnexal Carcinoma

\section{Introduction}

Skin cancer causes significant morbidity worldwide. ${ }^{1}$ However, apocrine-eccrine carcinomas are rare, with a reported incidence rate of 2.6 per 1 million personyears. Still, these adnexal neoplasms are associated with a prolonged course and a poor prognosis in the presence of metastatic disease, with a 5-year relative survival rate of $51 \%{ }^{2,3}$

Malignant chondroid syringoma (MCS), also called malignant mixed tumor of the skin, is an extremely uncommon eccrine sweat gland neoplasm with epithelial and mesenchymal components. Due to the absence of a distinct clinical presentation, it is difficult to distinguish from other cutaneous tumors. ${ }^{4}$

\section{Case presentation}

We present the case of a 64-year-old male with recurrent nodular skin lesions on his right arm. The patient underwent repeated excisions, followed by wide excision with axillary lymph node dissection. A $10-\mathrm{cm}$ firm, lobulated mass with skin ulceration and muscle involvement was removed. Microscopic examination revealed infiltrating nests of medium to large epithelial cells embedded in a chondromyxoid matrix with few scattered plasmacytoid myoepithelial cells (see Figure 1). There was brisk mitosis as well as large areas of tumor necrosis. All axillary lymph nodes were negative for tumor. The final histopathologic diagnosis was malignant chondroid syringoma. However, the patient was lost to follow-up.

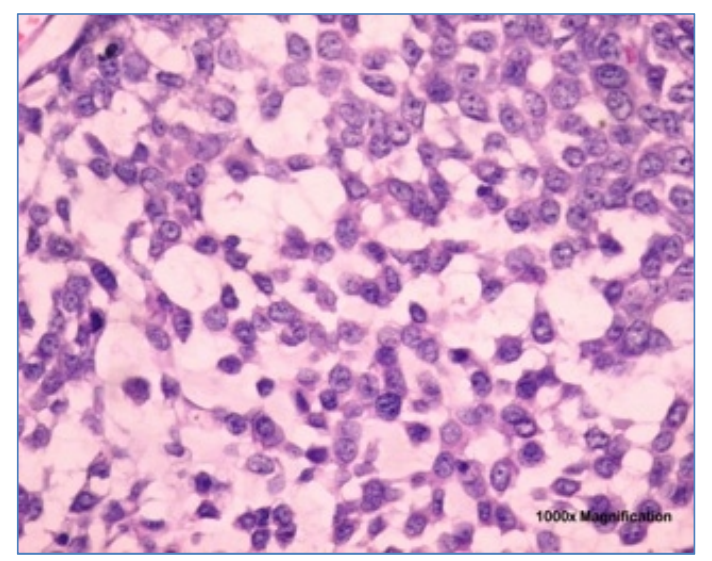

Figure 1: (1000x magnification). Cuboidal to polygonal tumor cells embedded in a chondromyxoid matrix, with moderate to abundant eosinophilic cytoplasm, round to ovoid nuclei, and prominent nucleoli.

Corresponding author: Ann Meredith Uao Garcia; Section of Medical Oncology, Department of Medicine, University of the Philippines Philippine General Hospital, Manila, Philippines.

Cite this article as: Garcia AM, Atun JM, Fernando G. Multifocal, recurrent malignant chondroid syringoma with visceral metastases: $A$ case report and literature review. Int J Cancer Ther Oncol. 2016; 4(1):4119. DOI: 10.14319/ijcto.41.19 
The patient's surgery was closely followed by the appearance of multiple similar-looking nodules over the scalp, face (including the buccal mucosa), trunk, right upper extremity, and right foot (see Figure 2). The patient also developed hepatomegaly accompanied by progressive weight loss and anorexia. Subsequent imaging studies revealed multiple pulmonary and hepatic nodules. The patient was then referred for palliative chemotherapy. At the time of consult, he had an Eastern Cooperative Oncology Group (ECOG) performance status of 2 and was advised a trial of doxorubicin-based chemotherapy. However, his clinical condition rapidly deteriorated and he eventually expired before starting treatment.

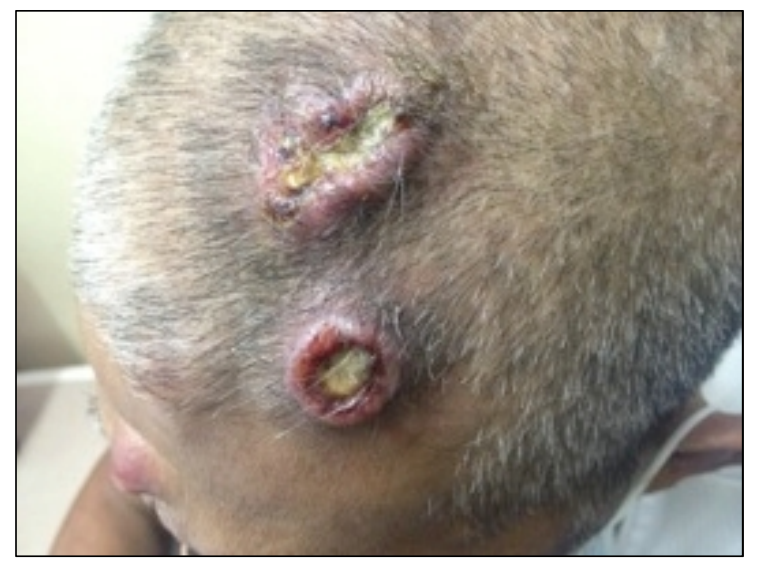

Figure 2: Multiple firm, erythematous nodules with indurated edges and central ulceration (scalp).

\section{Discussion}

Chondroid syringoma is a rare type of syringoma that histologically resembles benign mixed tumors of the salivary glands. ${ }^{5}$ Its cancerous subtype, malignant chondroid syringoma, is the rarest variant, with an estimated incidence of $<0.005 \%{ }^{6}$. In contrast to its benign counterpart, MCS is more common in women, affects a wider age range, and usually involves the trunk and extremities. ${ }^{7}$ Malignant lesions are usually much larger and appear as firm, circumscribed, asymmetrical skin nodules. They may progress very slowly, with late metastatic spread. ${ }^{4,6}$

Due to the lack of a distinct clinical presentation, MCS may be confused with various skin tumors, making histopathological and immunohistochemical examination of paramount importance due to differences in its treatment and prognosis. ${ }^{8}$ Upon literature review, MCS has been most commonly misdiagnosed as benign chondroid syringoma, unclassified benign sweat gland tumor, and basal cell carcinoma. Histopathologically, MCS consists of clusters of epithelial cells and ductal structures with intervening chondromyxoid matrix and scattered myoepithelial cells. The most reliable histologic features that favor malignancy include cellular atypia, nuclear pleomorphism, increased mitotic activity, focal necrosis, infiltrative borders, invasion of adjacent soft tissues, satellite tumor nodules, and metastasis.5,8 Immunohistochemical features include reactivity for epithelial markers such as cytokeratin (CK), epithelial membrane antigen (EMA), and carcinoembryonic antigen (CEA), as well as mesenchymal markers like vimentin, S-100, neuron-specific enolase (NSE), and glial fibrillary acidic protein (GFAP), similar to their salivary gland counterparts. ${ }^{9}$

MCS is an aggressive tumor with a significant risk for metastasis via hematogenous and lymphatic spread. ${ }^{4,7}$ It carries a mortality rate of approximately $25 \% .{ }^{10}$ It tends to follow an unpredictable course, with approximately $50 \%$ presenting with local recurrences, $42 \%$ with nodal metastases, and $40 \%$ with distant metastases. The most commonly identified site of distant metastasis was the lung, followed by bone and brain.11 Due to the small number of reported cases, prognostic factors are still difficult to establish, but these likely include size, histological type, lymph node involvement, and distant metastasis.

After a thorough literature search, 51 previous cases of MCS were retrieved.4,6-8,10-54 Including the present case, the age range was from 13 to 89 years, with a median age of 54 years. There was no particular age predilection, but there were slightly more cases in the fourth and seventh decades. More females were affected (58\%). The most commonly affected primary sites were the extremities (54\%), followed by the head and neck region (29\%) and the trunk (17\%). The present case is particularly exceptional because of the multifocal presentation and the presence of mucosal involvement. Most cases had recurrent disease (60\%), and nodal involvement was present in $37 \%$. Distant metastases were documented in $37 \%$ of all cases and in $71 \%$ of recurrent cases, most commonly affecting the lungs (24\%), followed by the central nervous system (10\%), pleura (10\%), bone (8\%), and liver (6\%). These data are quite consistent with previously published literature. However, it is more difficult to draw conclusions regarding mortality data as most cases had short follow-up times and not all authors mentioned the outcomes of their patients. Nevertheless, $17 \%$ of the cases included in this review died of progressive cancer disease. Surgery was the most widely utilized first-line treatment option, followed by radiotherapy and chemotherapy.

At present, there are no established guidelines for the treatment of apocrine-eccrine carcinomas, particularly for those with distant metastases. Complete surgical excision of the primary tumor with wide margins and dissection of involved lymph nodes is the mainstay of treatment for localized disease, as incomplete removal could result in recurrences. 4,19,24 Adjuvant radiotherapy and chemotherapy may also be recommended, but their 
definite roles are currently not yet well established as the rarity of this type of tumor precludes clinical trials. ${ }^{6,42}$ Previous reports suggest a possible survival advantage in patients with aggressive tumors receiving adjuvant radiotherapy. ${ }^{16,18,24}$ In particular, bone metastases and spinal cord compression have been shown to be responsive to local radiotherapy. ${ }^{6,41}$ On the other hand, the benefit of combination chemotherapy in metastatic disease has not yet been confirmed. Chemotherapeutic regimens that have been tried include: (1) Cyclophosphamide, vincristine, doxorubicin, dacarbazine (CYVADIC regimen) ${ }^{31,51}$; (2) Cyclophosphamide, vincristine, doxorubicin ${ }^{48}$; (3) Cyclophosphamide, vincristine, dactinomycin 6 ; (4) Cyclophosphamide, vincristine, vinblastine ${ }^{39}$; (5) Cisplatin, etoposide ${ }^{33}$; (6) Cisplatin, paclitaxel ${ }^{31}$; (7) 5-fluorouracil, cisplatin ${ }^{48}$; (8) 5-fluorouracil, leucovorin, cyclophosphamide, doxorubi$\operatorname{cin}^{33}$; (9) Tegafur, gimeracil, oteracil potassium ${ }^{25}$; and (10) Intralesional methotrexate ${ }^{35}$. However, no lasting clinical response has been observed with most of these regimens except for the CYVADIC protocol, with the treated patient still alive after 5 years of follow-up. ${ }^{51}$

\section{Conclusion}

To the authors' knowledge, this is the first reported case of malignant chondroid syringoma with a multifocal presentation and mucosal involvement. Because the disease has no distinct clinical presentation, its diagnosis relies on its characteristic histopathological and immunohistochemical findings. Complete surgical excision is the cornerstone of therapy for localized disease, while the role of other treatment modalities such as radiotherapy and chemotherapy has not yet been well established.

\section{Conflict of interest}

The authors declare that they have no conflicts of interest. The authors alone are responsible for the content and writing of the paper.

\section{References}

1. Galadari E, Mehregan AH, Lee KC. Malignant transformation of eccrine tumors. J Cutan Pathol. 1987;14(1):15-22.

2. Blake PW, Bradford PT, Devesa SS, Toro JR. Cutaneous appendageal carcinoma incidence and survival patterns in the United States: A population- based study. Arch Dermatol. 2010; 146(6):625-32.

3. Okada N, Ota J, Sato K, Kitano Y. Metastasizing eccrine sweat gland carcinoma. Arch Dermatol. 1984;120:768-9.

4. Famulski W, Kańczuga-Koda L, Niewiarowska $\mathrm{K}$, et al. Malignant mixed tumor of the skin: a case report and review of the literature. Prog Health Sci. 2013;3(1):154-8.
5. Elder DE. Lever's Histopathology of the Skin. $9^{\text {th }}$ ed. Philadelphia: Lippincott Williams \& Wilkins; 2005.

6. Gupta S, Kumar A, Padmanabhan A, Khanna S. Malignant Chondroid Syringoma: A Clinicopathological Study and a Collective Review. J Surg Oncol. 1982;20:139-44.

7. Bates AW, Baithun SI. Atypical mixed tumor of the skin. Am J Dermatopathol. 1998;20: 35-40.

8. Steinmetz JC, Russo BA, Ginsburg RE. Malignant chondroid syringoma with widespread metastasis. J Am Acad Dermatol. 1990; 22(5):845-7.

9. Padma M, Bharat Rao N. Giant Chondroid Syringoma - Case report of rare entity at unusual sites - cytohistological features. IOSR J Dent Med Sci. 2015;14(1):1-3.

10. Chang D, Shaletich C, Nogueira Zerbini MC. Siringoma condróide maligno: relato de caso e revisão da literatura. J Bras Patol Med Lab. 2007;43(3):191-4.

11. Araújo JL, de Aguiar GB, do Prado Aguiar U, et al. Malignant chondroid syringoma with central nervous system involvement. J Craniofac Surg. 2012;23(2):514-5.

12. Mondal RK, Acharyya S, Ray D, De S. Malignant chondroid syringoma in the anterior abdominal wall: a rare case report. J Evol Med Dent Sci. 2013;2(29):5402-6.

13. Nather A, Sutherland IH. Malignant transformation of a benign cutaneous mixed tumour. J Hand Surg. 1986;11:139-43.

14. Barnett MD, Wallack MK, Zuretti A, et al. Recurrent malignant chondroid syringoma: a case report and review of the literature. Am J Clin Oncol. 2000;23:227-32.

15. Shashikala P, Chandrashekhar HR, Sharma S, Suresh KK. Malignant chondroid syringoma. Indian J Dermatol Venereol Leprol. 2004;70:175-6.

16. Hong JJ, Elmore JF, Drachenberg CI, et al. Role of radiation therapy in the management of malignant chondroid syringoma. Dermatol Surg. 1995;21(9):731-5.

17. Hilton JMN, Blackwell JB. Metastasizing chondroid syringoma. J Pathol. 1973; 109:167-70.

18. Menéndez RH, Erice SG, Bas CA, et al. Spinal cord compression secondary to metastasis of malignant chondroid syringoma: case report. J Neurosurg Spine. 2015;22:310-3.

19. Rosborough D. Malignant mixed tumours of skin. Br J Surg. 1963;50(225):697-9.

20. Wasielewsky G, Algieri RD, Nowydwor B, et al. Siringoma Condroide Maligno: a Propósito de un Caso. Hosp Aeronáut Cent. 2012;7(2):124-6.

21. Webb JN, Stott WG. Malignant chondroid syringoma of the thigh. J Pathol. 1975;116:43-6. 
22. Trown K, Heenan PJ. Malignant mixed tumour of the skin. Pathol. 1994;26:237-43.

23. Sun TB, Chien HF, Huang SF, et al. Malignant chondroid syringoma. J Formos Med Assoc. 1996;95:575-8.

24. Mathiasen RA, Rasgon BM, Rumore G. Malignant Chondroid Syringoma of the Face: A First Reported Case. Otolaryngol Head Neck Surg. 2005;133:305-7.

25. Watarai A, Amoh Y, Aki R, et al. Malignant chondroid syringoma: report of a case with lymph node metastasis 12 years after local excision. Dermatol Online J. 2011;17(9):5.

26. Malik R, Saxena A, Kamath N. A rare case of malignant chondroid syringoma of scalp. Indian Dermatol Online J. 2013;4:236-8.

27. Requena C, Brotons S, Sanmartín 0, et al. Malignant chondroid syringoma of the face with bone invasion. Am J Dermatopathol. 2013;35:395-8.

28. Kiely JL, Dunne B, McCabe M, McNicholas WT. Malignant chondroid syringoma presenting as multiple pulmonary nodules. Thorax. 1997;52:395-6.

29. Harrist TJ, Aretz TH, Mihm MC, et al. Cutaneous malignant mixed tumor. Arch Dermatol. 1981;117:719-24.

30. Takahashi H, Ishiko A, Kobayashi M, et al. Malignant chondroid syringoma with bone invasion: a case report and review of the literature. Am J Dermatopathol. 2004;26(5): 403-6.

31. Yogi V, Singh OP, Tiwari V. Malignant Chondroid Syringoma: A Case Report with Review of Literature. Res Rev J Med Health Sci. 2014;3(2):29-32.

32. Pinto de Moraes H, Herrera GA, Mendonca AM, Estrela RR. Metastatic malignant mixed tumor of the skin. Appl Pathol. 1986;4:199-208.

33. Solomonov A, Rosenblatt E, Ben-Izhak O, et al. High-Dose-Rate Endobronchial Brachytherapy in Endobronchial Metastatic Malignant Chondroid Syringoma. Respiration. 2001;68:406-10.

34. Sharville DE. Mixed salivary type tumours of the skin with malignant recurrence. Br J Derm. 1962;74:103-4.

35. Matz LR, McCully DJ, Stokes BA. Metastasizing chondroid syringoma: case report. Pathol. 1969;1(1):77-81.

36. Schremmer CN. Rezidivierender und metastasierender Hauttumor vom Typ der Speicheldrusenmischgeschwulste. Zbl Allg Pathol. 1970;113:545-51.

37. Lucas GL, Nordby EJ. Sweat gland carcinoma of the hand. Hand. 1974;6:98-102.
38. Dissanayake RVP, Salm R. Sweat-gland carcinomas: prognosis related to histological type. Histopathol. 1980;4:445-66.

39. Redono C, Rocamora A, Villoria F, Garcia M. Malignant Mixed Tumor of the Skin. Cancer. 1982;49:1690-6.

40. Ishimura E, lwamoto $H$, Kobashi $Y$, et al. Malignant chondroid syringoma. Cancer. 1983;52:1966-73.

41. Devine P, Sarno RC, Ucci AA. Malignant cutaneous mixed tumor. Arch Dermatol. 1984;120:576-7.

42. Shvili D, Rothem A. Fulminant metastasizing chondroid syringoma of the skin. Am J Dermatopathol. 1986;8:321-5.

43. Clark P. Malignant chondroid syringoma. Conn Med. 1987;51:569-72.

44. Hermann G, Moss D, Norton KI, Guttenberg ME. Case report 450: Skeletal metastases secondary to malignant chondroid syringoma. Skeletal Radiol. 1987;16:657-59.

45. Sanchez Yus E, Aguilar A, Urbina F, et al. Malignant cutaneous mixed tumor. A new case with unusual clinical features. Am J Dermatopathol. 1988;10:330-4.

46. Watson JAS, Walker MM, Smith NP, et al. Malignant chondroid syringoma: a rare cause of secondary bone tumour. Clin Exp Dermatol. 1991;16:306-7.

47. Vohra S, Bates AW, Baithun SI. A rare adnexal tumour of the hallux: malignant chondroid syringoma. Foot. 1996;6:175-7.

48. Kim DH, Lee CW, Lee KH, Hyun MS. A Case of Malignant Chondroid Syringoma with Lung Metastasis. J Korean Cancer Assoc. 1997;29(6):1119-24.

49. Agrawal V, Gupta RL, Kumar S, et al. Malignant chondroid syringoma. J Dermatol. 1998;25(8):547-9.

50. Nicolaou S, Dubec JJ, Munk PL, et al. Malignant chondroid syringoma of the skin: magnetic resonance imaging features. Australas Radiol. 2001;45:240-3.

51. Medina Henriquez JA, Navarro Garcia R, Nagel D, Foucher G. Malignant chondroid syringoma of the hand: a case report. Scand J Plast Reconstr Surg Hand Surg. 2001;35: 437-9.

52. Sugita K, Kobayashi M, Hino R, et al. Malignant chondroid syringoma of the scalp. Skin Cancer. 2005;20(2):142-5.

53. Rahman A, Dedhia H, Iluyomade O, Graeber G. A rare presentation of malignant chondroid syringoma as a lung mass. Chest. 2007;132(4):691.

54. Tural D, Selçukbiricik F, Günver F, et al. Facial localization of malignant chondroid syringoma: a rare case report. Case Rep Oncol Med. 2013;907980:1-3. 